\title{
FORMULATION, IN VITRO AND EX VIVO CHARACTERIZATION OF MUCOADHESIVE BUCCAL TABLETS FOR ANTIHYPERTENSIVE DRUG
}

\author{
HIMABINDU PEDDAPALLI*, VASUDHA BAKSHI, NARENDER BOGGULA
}

Department of Pharmaceutics, School of Pharmacy, Anurag Group of Institutions, Venkatapur, Ghatkesar- 500 088, Telangana, India. E mail: bindu.sweety369@gmail.com

Received: 21 March 2018, Revised and Accepted: 09 May 2018

\section{ABSTRACT}

Objective: Olmesartan belongs to a class of angiotensin II receptor blockers. It is used in the treatment of hypertension. However, it undergoes extensive hepatic first-pass metabolism, resulting in low oral bioavailability is about $26 \%$. The aim of this study was to prepare and evaluate the mucoadhesive buccal tablets of olmesartan with a goal to increase the bioavailability and improve the patient compliance.

Methods: Mucoadhesive buccal tablets were prepared by a direct compression technique using mucoadhesive polymers such as hydroxypropyl methylcellulose (HPMC K4M), sodium carboxymethylcellulose (SCMC), and Carbopol 934P. The tablets were evaluated for weight variation, thickness, hardness, friability, surface $\mathrm{pH}$, swelling index, drug content uniformity, in vitro drug release, ex vivo mucoadhesive strength, ex vivo mucoadhesive time, and ex vivo permeation studies. The release kinetics was calculated to determine the drug release mechanism.

Results: The physicochemical properties of all the formulations were shown to be within the limits. The optimized buccal tablets F2, F7, and F11 showed satisfactory drug release rates with the diffusion controlled mechanism. Optimized buccal tablets developed for olmesartan possess reasonable mucoadhesive strength, mucoadhesive time, and surface $\mathrm{pH}$ was in an acceptable salivary pH 6.76 $\pm 0.28-6.89 \pm 0.34$. The ex vivo permeation studies for optimized tablets were shown satisfactory drug permeation and could meet the target flux $0.991 \mathrm{mg} \mathrm{h}^{-1} \mathrm{~cm}^{-2}$.

Conclusion: The obtained results could be used as a platform to develop the buccal delivery of this drug, which bypasses the first-pass metabolism and results in the improvement of bioavailability. Hence, the present study concludes that the olmesartan could be delivered through the buccal route.

Keywords: Mucoadhesive buccal tablets, Olmesartan, Direct compression method, ex vivo permeation studies.

(c) 2018 The Authors. Published by Innovare Academic Sciences Pvt Ltd. This is an open access article under the CC BY license (http://creativecommons. org/licenses/by/4. 0/) DOI: http://dx.doi.org/10.22159/ajpcr.2018.v11i8.26126

\section{INTRODUCTION}

Oral drug administration is the most preferred and common route for drug delivery. Although, sometimes it also entails with certain major disadvantages such as first-pass metabolism, gastrointestinal enzymatic degradation, and poor bioavailability. These difficulties have provided the impulsion for exploring alternative routes for the delivery of drugs, which includes pulmonary, ocular, nasal, rectal, vaginal, and buccal [1]. Transmucosal routes of drug delivery (i.e. the mucosal linings of the nasal, rectal, vaginal, ocular, and oral cavity) offer attractive possible routes for administration of drugs and may avoid the significant drawbacks of peroral and parenteral administration for systemic effect [2]. The oral cavity, however, is a highly accepted route for both local and systemic drug delivery [3]. Indeed, buccal delivery is increasingly being considered to be the preferred route for many drug classes [4]. The buccal delivery is in which drug administration through the mucosal membranes lining of the cheeks to systemic circulation [5]. Buccal mucosa is a potential site for the delivery of drugs to the systemic circulation, a drug administered through the buccal mucosa enters directly the systemic circulation, thereby minimizing the firstpass hepatic metabolism and adverse gastrointestinal effect [6]. The oral mucosa, mainly the buccal site rather attractive for drug delivery [7], because the mucosa is relatively permeable with a rich blood supply, it is easily accessible, relatively immobile mucosa, suitable for administration of retentive dosage forms, termination of therapy at any time, comparatively less susceptibility to enzymatic activity, and useful for pediatric and geriatric patients. Hence, various mucoadhesive dosage forms were prepared for oral delivery, in the form of adhesive tablets [8-13], adhesive gels, buccal ointments [14,15], Bioadhesive Wafers [16], Bioadhesive lozenges [17], Bioadhesive Microparticles [18], and adhesive patches $[19,20]$.
Olmesartan belongs to a class of drugs called angiotensin II receptor blockers (ARBs). It is approved and used for the treatment of hypertension. It may be used alone or in combination with other antihypertensive agents [21]. The molecular weight of drug is $446.511 \mathrm{~g} / \mathrm{mol}$. Olmesartan has excellent lipophilicity, so the drug can get easily absorbed and permeable through buccal mucosa. The halflife is approximately 6-7 h. Orally administered olmesartan was rapidly absorbed from the gastrointestinal tract but undergoes extensive firstpass metabolism, resulting in low oral bioavailability is about $26 \%$. Olmesartan dose-dependently reduces the blood pressure through arterial vasodilation and reduced sodium retention, as do other ARBs [22]. Based on the above criteria, it was considered an essential alternative to develop buccal drug delivery system for delivery of olmesartan, which can improve its bioavailability by avoiding hepatic metabolism using suitable mucoadhesive polymers. Hence, the aim of this study was to prepare mucoadhesive buccal tablets of olmesartan to ensure satisfactory drug release within oral cavity with the use of the optimum polymer.

\section{MATERIALS AND METHODS}

\section{Materials}

Olmesartan (Drug) was a gift sample from Cipla, Ltd., Mumbai, India. Hydroxypropyl methylcellulose K4M (HPMC K4M) and sodium carboxymethyl cellulose (SCMC) were gift samples from Horizon Pharma, Gujarat, India. Carbopol 934P was a gift sample from Dr. Reddys Laboratories, Hyderabad, India. Microcrystalline cellulose 102 was purchased from Apotex Pharmachem (Bengaluru, India). Mannitol was purchased from S.D. Fine Chem. Ltd., Mumbai, India. Talc and magnesium stearate were purchased from HiMedia Laboratories Pvt. Ltd., Mumbai, India. 
Methods

\section{Preformulation studies}

Determination of absorption maxima values $\left(\lambda_{\max }\right)$ using ultraviolet (UV)-visible spectrophotometer

Standard stock solution of olmesartan $(100 \mu \mathrm{g} / \mathrm{ml})$ was prepared in pH 6.8 phosphate buffer. For the selection of analytical wavelength, a solution of olmesartan of concentration $30 \mu \mathrm{g} / \mathrm{ml}$ was prepared by appropriate dilution of the standard stock solution with phosphate buffer $\mathrm{pH} 6.8$ and scanned in the spectrum range from 200 to $400 \mathrm{~nm}$. From the overlain spectrum of the drug, wavelength $256 \mathrm{~nm}$ was selected for analysis. The wavelength with maximum absorption was chosen for further analysis (Fig. 1).

Preparation of standard graph of olmesartan in $\mathrm{pH} 6.8$ phosphate buffer and $\mathrm{pH} 7.4$ phosphate buffer by UV-visible spectrophotometer

The stock solution was freshly prepared by dissolving $100 \mathrm{mg}$ of olmesartan in $6.8 \mathrm{pH}$ phosphate buffers in a $100 \mathrm{ml}$ volumetric flask and then making up the solution up to the mark using $6.8 \mathrm{pH}$ phosphate buffers for obtaining the solution of strength $1000 \mu \mathrm{g} / \mathrm{ml}$ (stock I). From this primary stock, $10 \mathrm{ml}$ of this solution is diluted to $100 \mathrm{ml}$ with distilled water to obtain a solution of strength $100 \mu \mathrm{g} / \mathrm{ml}$ (stock II). From this secondary stock $0.2,0.4,0.8,1.0,2.0,3.0,4.0,5.0$, and $6.0 \mathrm{ml}$ were taken separately and made up to $10 \mathrm{ml}$ with $\mathrm{pH} 6.8$ phosphate buffer, to produce $2,4,8,10,20,30,40,50$, and $60 \mu \mathrm{g} / \mathrm{ml}$, respectively. The absorbance was measured at $256 \mathrm{~nm}$ using a UVvisible spectrophotometer (Elico Pvt., Ltd., Hyderabad). Similarly, standard graph of olmesartan in $\mathrm{pH} 7.4$ phosphate buffer was plotted (Fig. 2 and 3, Table 1)

Drug excipients compatibility studies

Fourier transform infrared (FTIR) spectroscopy

The FTIR spectra for the samples were obtained using potassium bromide $(\mathrm{KBr})$ disk method by FTIR spectrophotometer. Pure drug olmesartan, physical mixture of olmesartan and HPMC K4M, physical mixture of olmesartan and SCMC and physical mixture of olmesartan and Carbopol 934P were prepared and subjected to FTIR study. About 2-3 mg of sample was mixed with dried $\mathrm{KBr}$ of equal weight and compressed to form a $\mathrm{KBr}$ disk. The samples were scanned from 400 to $4000 \mathrm{~cm}^{-1}$ spectral region with a resolution of $4 \mathrm{~cm}^{-1}$.

\section{Ex vivo drug permeation studies through goat buccal mucosa}

\section{Tissue isolation}

The objective of this study was to investigate the permeability of buccal mucosa to olmesartan. Goat buccal tissue was taken from a local slaughter-house. It was collected within $10 \mathrm{~min}$ after the slaughter of the goat and tissue was stored in Krebs buffer solution. It was transported immediately to the laboratory and was used within $2 \mathrm{~h}$ of isolation of buccal tissue $[23,24]$. The buccal epithelium was carefully separated from the underlying connective tissue with surgical technique, and

Table 1: Absorbance of olmesartan against different concentrations at $\lambda_{\text {max }}(256 \mathrm{~nm})$ in phosphate buffer pH 6.8 and phosphate buffer pH 7.4

\begin{tabular}{lll}
\hline Concentration $(\boldsymbol{\mu g} / \mathrm{ml})$ & \multicolumn{2}{l}{ Absorbances } \\
\cline { 2 - 3 } & $\begin{array}{l}\mathbf{6 . 8} \mathbf{~ p H} \text { Phosphate } \\
\text { buffer }\end{array}$ & $\begin{array}{l}\mathbf{7 . 4} \mathbf{~ p H} \text { Phosphate } \\
\text { buffer }\end{array}$ \\
\hline 2 & 0.053 & 0.029 \\
4 & 0.082 & 0.045 \\
8 & 0.143 & 0.119 \\
10 & 0.191 & 0.148 \\
20 & 0.323 & 0.271 \\
30 & 0.471 & 0.411 \\
40 & 0.611 & 0.552 \\
50 & 0.745 & 0.684 \\
60 & 0.893 & 0.816 \\
\hline
\end{tabular}

then the remaining buccal mucosa was carefully trimmed with the help of surgical scissors to a uniform thickness (Fig. 4). Sufficient care was taken to prevent any damage to the buccal epithelium. Finally, the membrane was allowed to equilibrate for approximately $1 \mathrm{~h}$ in receptor buffer to regain the lost elasticity [25].

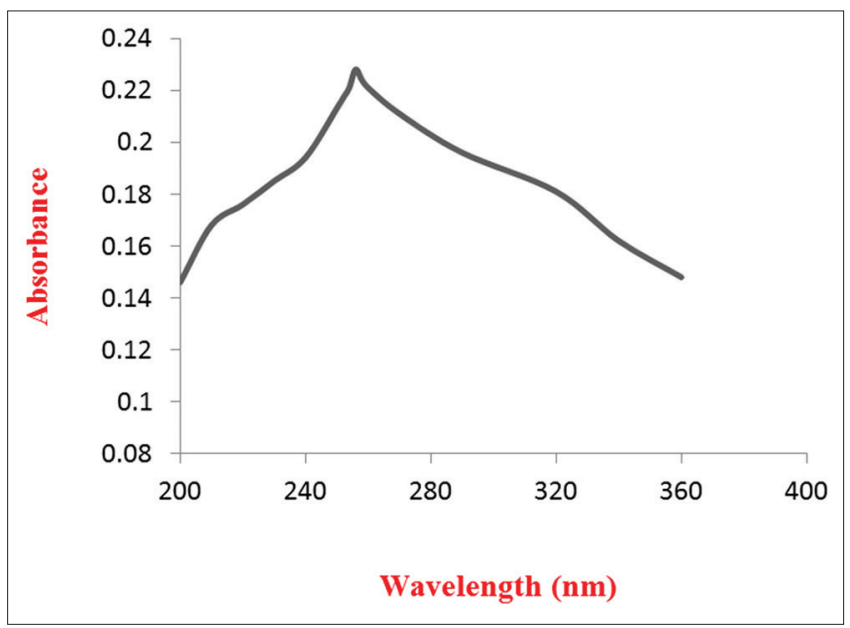

Fig. 1: Ultraviolet absorption spectrum of olmesartan in phosphate buffer pH 6.8

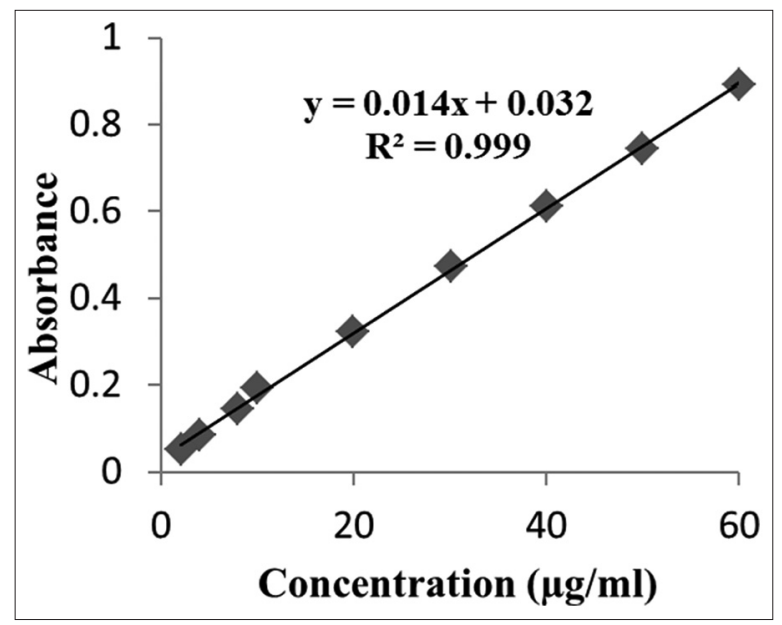

Fig. 2: Standard graph of olmesartan in pH 6.8 phosphate buffer

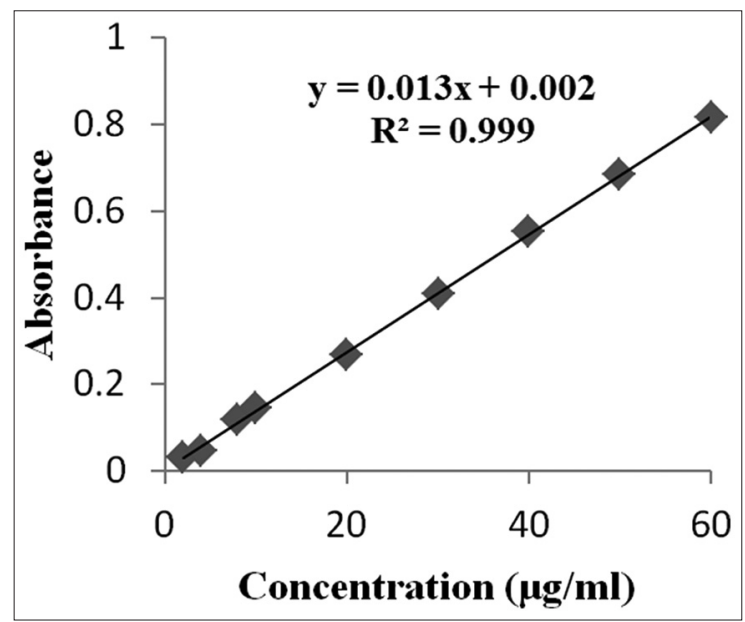

Fig. 3: Standard graph of olmesartan in pH 7.4 phosphate buffer 
Table 2: Composition of olmesartan buccal tablets containing hydroxylpropyl methylcellulose and sodium carboxymethyl cellulose

\begin{tabular}{|c|c|c|c|c|c|c|c|c|c|c|}
\hline \multirow[t]{2}{*}{ Ingredients } & \multicolumn{10}{|c|}{ Formulations (weight in mg) } \\
\hline & F1 & F2 & F3 & F4 & F5 & F6 & F7 & F8 & F9 & F10 \\
\hline Drug: polymer & $1: 0.5$ & $1: 1$ & $1: 2$ & $1: 2.5$ & $1: 3$ & 1:0.5 & $1: 1$ & 1:1.5 & $1: 2$ & $1: 2.5$ \\
\hline Olmesartan & 40 & 40 & 40 & 40 & 40 & 40 & 40 & 40 & 40 & 40 \\
\hline HPMC K4M & 20 & 40 & 80 & 100 & 160 & - & - & - & - & - \\
\hline SCMC & - & - & - & - & - & 20 & 40 & 60 & 80 & 100 \\
\hline MCC102 & 170 & 150 & 110 & 90 & 30 & 170 & 150 & 130 & 110 & 90 \\
\hline Mannitol & 15 & 15 & 15 & 15 & 15 & 15 & 15 & 15 & 15 & 15 \\
\hline Magnesium stearate & 3 & 3 & 3 & 3 & 3 & 3 & 3 & 3 & 3 & 3 \\
\hline Talc & 2 & 2 & 2 & 2 & 2 & 2 & 2 & 2 & 2 & 2 \\
\hline Total tablet weight (in mg) & 250 & 250 & 250 & 250 & 250 & 250 & 250 & 250 & 250 & 250 \\
\hline
\end{tabular}

HPMC K4M: Hydroxylpropyl methylcellulose, SCMC: Sodium carboxymethylcellulose

Table 3: Composition of olmesartan buccal tablets containing Carbopol 934P

\begin{tabular}{llllll}
\hline \multirow{2}{*}{ Ingredients } & \multicolumn{5}{l}{ Formulations (weight in mg) } \\
\cline { 2 - 6 } & F11 & F12 & F13 & F14 & F15 \\
\hline Drug: polymer & $1: 0.5$ & $1: 1$ & $1: 1.5$ & $1: 2$ & $1: 2.5$ \\
Olmesartan & 40 & 40 & 40 & 40 & 40 \\
Carbopol 934P & 20 & 40 & 60 & 80 & 100 \\
MCC102 & 170 & 150 & 130 & 110 & 90 \\
Mannitol & 15 & 15 & 15 & 15 & 15 \\
Magnesium stearate & 3 & 3 & 3 & 3 & 3 \\
Talc & 2 & 2 & 2 & 2 & 2 \\
Total tablet weight (in $\mathrm{mg})$ & 250 & 250 & 250 & 250 & 250 \\
\hline
\end{tabular}

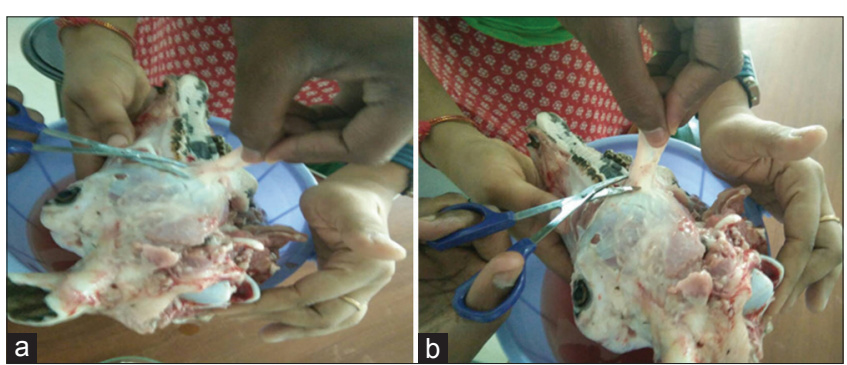

Fig. 4: ( $a$ and $b$ ) Isolation of goat buccal membrane by surgical technique

\section{Procedure}

Ex vivo permeation study of olmesartan was performed through the goat buccal mucosa using modified Franz diffusion cell. The isolated buccal epithelium was carefully mounted between the two compartments of a modified Franz diffusion cell, and the membrane was allowed to equilibrate for approximately $1 \mathrm{~h}$. After the buccal membrane was equilibrated for $1 \mathrm{~h}$ with $\mathrm{pH} 7.4$ phosphate buffer solution between both the chambers, the receiver compartment was filled with $25 \mathrm{ml}$ fresh phosphate buffer solution ( $\mathrm{pH}$ 7.4), and the donor compartment was charged with $4 \mathrm{ml}(1 \mathrm{mg} / \mathrm{ml})$ of drug solution. The entire setup was placed over magnetic stirrer at $50 \mathrm{rpm}$, and the temperature was maintained at about $37^{\circ} \mathrm{C}$. The $2 \mathrm{ml}$ of samples were collected at predetermined time intervals $0.5,1.0,1.5,2.0,3.0,4.0,5.0$, and $6.0 \mathrm{~h}$ from receptor compartment and replaced with an equal volume of fresh buffer solution and stored under refrigerated conditions till the analysis was carried out. All the experiments were performed in triplicates. Finally, the amount of drug permeated through the buccal mucosa was determined by measuring the absorbance at $256 \mathrm{~nm}$ using a UV-visible spectrophotometer (Elico Pvt., Ltd., Hyderabad). The studies were repeated in triplicate $(n=3)$, and the mean was calculated.

\section{Preparation of mucoadhesive buccal tablets}

Buccal tablets were prepared by a direct compression method $[9,26]$. The required quantities of the drug, polymer, and excipients were accurately weighed, and all the ingredients were screened through sieve no.40, to get uniform particle size. The drug and the all ingredients except lubricants were taken into a polythene bag with the help of stainless steel spatula, and the ingredients were mixed in the order of ascending weights and blended for about $10 \mathrm{~min}$. After uniform mixing of ingredients, lubricant and glidant were added and again mixed for 2 min (Tables 2 and 3). The prepared blend of each formulation was compressed using $6 \mathrm{~mm}$ punch on a tablet punching machine.

\section{Evaluation of the prepared buccal tablets \\ Weight variation test}

Twenty tablets from each batch were individually weighed on a digital balance. The average weight and standard deviation were calculated. The percent deviation was calculated using the following formula.

$$
\% \text { Deviation }=\frac{\text { Individual Weight }- \text { Average weight }}{\text { Average weight }} \times 100
$$

Thickness test

The thickness of buccal tablets was measured for 10 individual tablets from each batch by using Vernier calipers. The average thickness and standard deviation were reported.

\section{Hardness test}

Tablet hardness was measured for 6 tablets from each batch using a Pfizer hardness tester. The mean \pm standard deviation values were calculated for all the formulations.

\section{Friability test}

Roche friabilator was used to determine the friability by the following procedure. Pre-weighed tablets (10 tablets) were placed in the friabilator. The tablets were rotated at $25 \mathrm{rpm}$ for $4 \mathrm{~min}$ (100 rotations). At the end of the test, the tablets were re-weighed; loss in the weight of tablet was measured in percentage using following formula. The studies were repeated in triplicate $(n=3)$, and the mean was calculated.

$$
\% \text { Friability }=\frac{\text { Individual Weight }- \text { Average weight }}{\text { Average weight }} \times 100
$$

Where $\mathrm{W}_{1}=$ Initial weight of 10 tablets

$\mathrm{W}_{2}=$ Weight of the 10 tablets after testing

\section{Assay of tablets}

Ten tablets were weighed and grounded in a mortar with pestle to get fine powder; powder equivalent to the mass of one tablet was dissolved in $100 \mathrm{ml}$ of $\mathrm{pH} 6.8$ of phosphate buffer. The solution was filtered through $0.45 \mu \mathrm{m}$ filter paper and diluted approximately with $\mathrm{pH} 6.8$ phosphate buffer and the drug content was estimated using UV-visible spectrophotometer at $256 \mathrm{~nm}$.

\section{In vitro drug release studies}

The drug release from the bioadhesive buccal tablets was studied using the USP type II dissolution test apparatus. The dissolution medium 
consisted of $500 \mathrm{ml}$ of phosphate buffer $\mathrm{pH}$ 6.8. The release was performed at $37^{\circ} \mathrm{C} \pm 0.5^{\circ} \mathrm{C}$, with a rotation speed of $50 \mathrm{rpm}$. Tablets were meant to release the drug from only one side; therefore, an impermeable backing membrane was placed on the other side of the tablet. The tablet was further fixed to a $2 \times 2 \mathrm{~cm}$ glass slide with a solution of cyanoacrylate adhesive. Samples $(5 \mathrm{ml})$ were withdrawn at predetermined time intervals up to $6 \mathrm{~h}$ and replaced with fresh medium and analyzed using UV-visible spectrophotometer at $256 \mathrm{~nm}$. The cumulative percentage release and standard deviation were calculated $[12,19]$.

\section{Swelling studies for buccal tablet}

Water uptake of the tablets was determined gravimetrically in phosphate buffer, $\mathrm{pH}$ 6.8. Buccal tablets were weighed individually (designated as $\mathrm{W}_{1}$ ) and the tablets were attached to pre-weighed glass support using a cyanoacrylate adhesive sealant. The supports with tablets were immersed into the phosphate buffer at $37^{\circ} \mathrm{C}$. At predetermined time intervals, the device was removed from the media, blotted with tissue paper to remove excess surface water, reweighed $\left(\mathrm{W}_{2}\right)$. This experiment was performed in triplicate. The swelling index (water uptake) was calculated according to the following equation.

Swelling index $=\frac{\mathrm{W} 1-\mathrm{W} 2}{\mathrm{~W} 1} \times 100$

Where W1 and W2 are the weights of dry and swollen devices, respectively.

The swelling of the formulations was dependent on both, the type and concentration of the polymer used.

\section{Surface pH study}

The bioadhesive tablet was allowed to swell by keeping it in contact with $1 \mathrm{ml}$ of distilled water for $2 \mathrm{~h}$ at room temperature. The $\mathrm{pH}$ was measured by bringing the pH-meter electrode, in contact with the surface of the tablet and allowing it to equilibrate for $1 \mathrm{~min}$ [27].

\section{Ex vivo mucoadhesive strength}

A modified balance method was used for determining the ex vivo mucoadhesion strength $[23,24]$. Goat buccal mucosa was used as the model substrate, and phosphate buffer $\mathrm{pH} 6.8$ was used as the moistening fluid. Freshly excised goat buccal mucosa was obtained from the local slaughterhouse used within $2 \mathrm{~h}$ of slaughter. The tablet was laid onto the model membrane under manual pressure of $5 \mathrm{~min}$. Bioadhesive strength was measured in terms of weight in grams of water required to detach the tablet from the goat buccal mucosa [28]. The addition of water was stopped when the tablet was detached from buccal mucosa. The weight of water required to detach the tablet from buccal mucosa was noted as ex vivo mucoadhesive strength. Mucoadhesive strength was performed for optimized formulations in triplicate, and average mucoadhesive strength was determined.

\section{Ex vivo mucoadhesion time}

The ex vivo mucoadhesion time was examined $(\mathrm{n}=3)$ for optimized formulations, after application of the buccal tablet on freshly cut goat buccal $[24,29]$. The fresh goat buccal mucosa was tied on the glass side, and a mucoadhesive core side of each tablet was wetted with 2 drops of phosphate buffer $\mathrm{pH} 6.8$ and pasted to the goat buccal mucosa by applying a light force with a fingertip for $30 \mathrm{~s}$. The glass slide was then put in the beaker, which was filled with $200 \mathrm{ml}$ of the phosphate buffer $\mathrm{pH} 6.8$ and kept at $37^{\circ} \mathrm{C} \pm 1^{\circ} \mathrm{C}$. After 2 min, a slow stirring rate was applied to simulate the buccal cavity environment, and tablet adhesion was monitored for $8 \mathrm{~h}$. The time for detaching from the goat buccal mucosa was recorded as the mucoadhesion time.

Ex vivo permeation of olmesartan through goat buccal membrane from optimized buccal tablets

Ex vivo permeation of olmesartan from the buccal tablet for the optimized formulations (F2, F7, and F11) through goat buccalmembrane was studied [30]. Buccal membrane was isolated as described in tissue isolation section. The membrane was mounted over a modified Franz diffusion cell. The buccal tablet was sandwiched between the buccal mucosa and dialysis membrane, so as to secure the patch tightly from getting dislodged from the buccal membrane. $25 \mathrm{ml}$ of phosphate buffer pH 7.4 was placed in the receptor compartment. The entire set up was placed over magnetic stirrer, and the temperature was maintained at $37^{\circ} \mathrm{C}$. Samples of $2 \mathrm{ml}$ were collected at predetermined time points up to $6 \mathrm{~h}$ from receptor compartment and replaced with an equal volume of buffer. The amount of drug permeated from optimized formulation through the buccal mucosa was then determined by measuring the absorbance at $256 \mathrm{~nm}$ using a UV-visible spectrophotometer. The experiments were performed in triplicate $(n=3)$, the cumulative percentage drug permeated was calculated.

\section{Stability of buccal tablets}

Stability studies of buccal tablets were performed for optimized formulations (F2, F7, and F11) in normal human saliva [31]. The saliva was collected from humans (aged 22-26) and filtered through Whatman $(0.2 \mu \mathrm{m})$ filter paper. Buccal tablets were placed in separate Petri dishes containing $5 \mathrm{ml}$ of human saliva and placed in a temperature-controlled oven for $6 \mathrm{~h}$ at $37 \pm 0.2^{\circ} \mathrm{C}$. At regular time intervals $(0,2,4$, and $6 \mathrm{~h})$, the buccal tablets were examined for change in color, integrity, and change in $\mathrm{pH}$ [14]. The experiments were repeated in triplicate $(\mathrm{n}=3)$ in a similar manner.

In vitro ex vivo correlation between cumulative percentage drug released in vitro and percentage drug permeated ex vivo of optimized olmesartan buccal tablets

A possible in vitro ex vivo correlation was performed for percentage drug released in vitro and percentage drug permeated ex vivo for optimized formulations [32].

\section{RESULTS AND DISCUSSION}

Determination of absorption maximum values

An UV-visible spectrophotometric method was used for estimation of absorption maxima of olmesartan. The $\lambda_{\max }$ of olmesartan $(30 \mu \mathrm{g} / \mathrm{ml})$ in $6.8 \mathrm{pH}$ phosphate buffer was scanned in UV-visible spectrophotometer in the wavelength range of $200-400 \mathrm{~nm}$ and found to have a maximum absorbance at $256 \mathrm{~nm}$.

Preparation of standard graph of olmesartan in $\mathrm{pH} 6.8$ phosphate buffer and pH 7.4 phosphate buffer by UV-visible spectrophotometer

Different concentrations of olmesartan were prepared in phosphate buffer $\mathrm{pH} 6.8$ and phosphate buffer $\mathrm{pH} 7.4 \quad(2-60 \mu \mathrm{g} / \mathrm{ml})$, and absorbance values at $\lambda_{\text {max }}(256 \mathrm{~nm})$ were noted. The calibration curves showed good linearity with a correlation coefficient of $\mathrm{R}^{2} 0.999$.

\section{Drug-excipient compatibility studies}

\section{FTIR spectroscopy studies}

The potential chemical interaction between drug and polymer may change the therapeutic efficacy of the drug. FTIR spectroscopic studies were carried out, to investigate the possibility of any chemical interaction between drug and polymers used in the preparation of tablets. The different samples were analyzed over the range 400$4000 \mathrm{~cm}^{-1}$. The FTIR spectrum of olmesartan showed principal bands at $2923.56-2995.87 \mathrm{~cm}^{-1}$ for $\mathrm{C}-\mathrm{H}, 1708-1832 \mathrm{~cm}^{-1}$ for C-O, and $3000-$ $3100 \mathrm{~cm}^{-1}$ for $\mathrm{N}-\mathrm{H}$. These peaks can be considered as characteristic peaks of olmesartan. These FTIR bands of the drug remain intact and also no new peak was found in both the spectra of the drug and physical mixture. This indicates the absence of interaction between drug and mucoadhesive polymers used and results were shown in figures 5-8.

\section{Ex vivo drug permeation studies through goat buccal mucosa}

Goat buccal mucosa had been the most frequently chosen model tissue for ex vivo permeation studies because of its similarity to human tissue in terms of thickness and is easily available in large quantities from the slaughterhouse. 


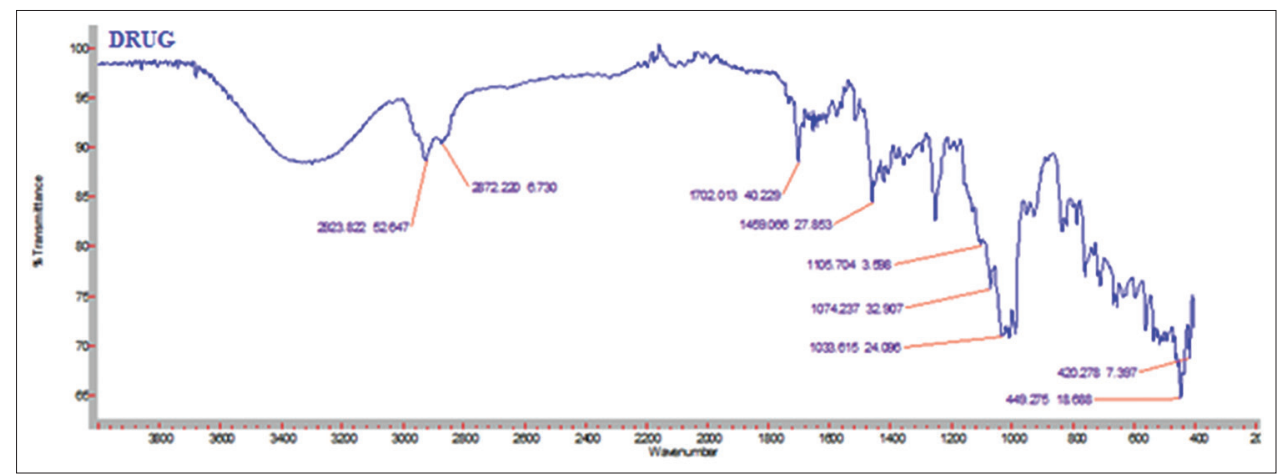

Fig. 5: Fourier Transform Infrared spectrum of olmesartan

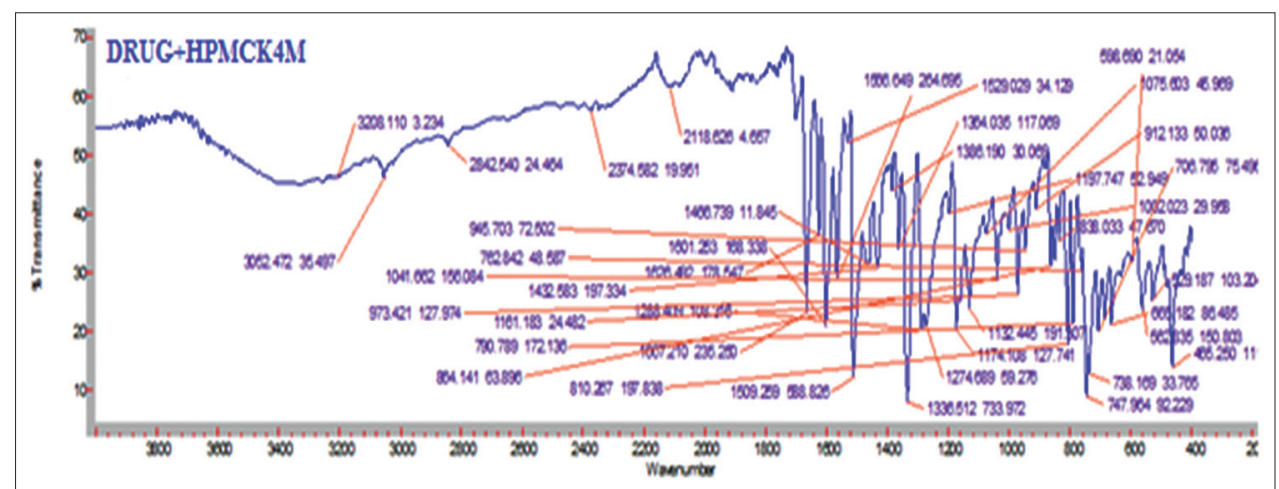

Fig. 6: Fourier transform infrared spectrum of a physical mixture of olmesartan and hydroxypropyl methylcellulose

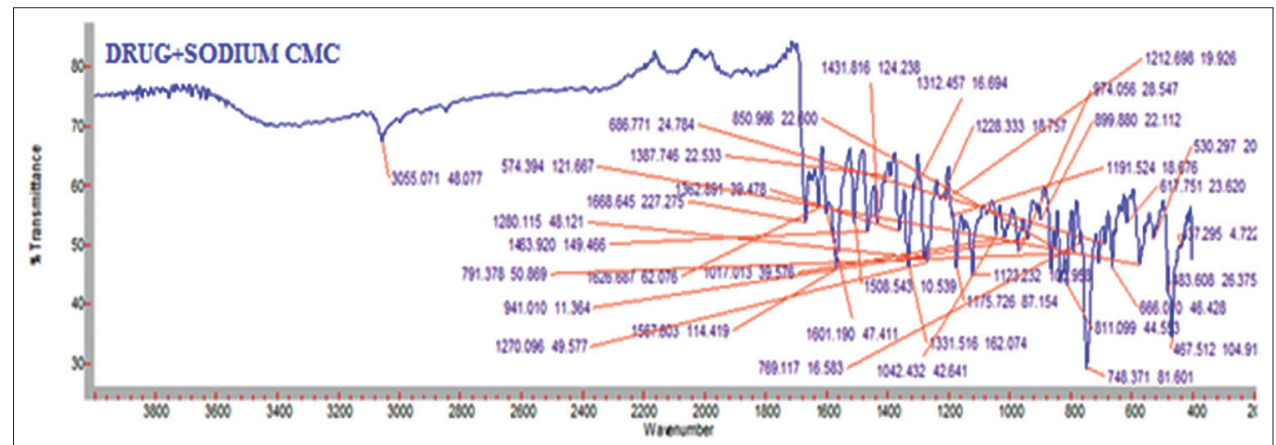

Fig. 7: Fourier transform infrared spectrum of a physical mixture of olmesartan and sodium carboxymethylcellulose

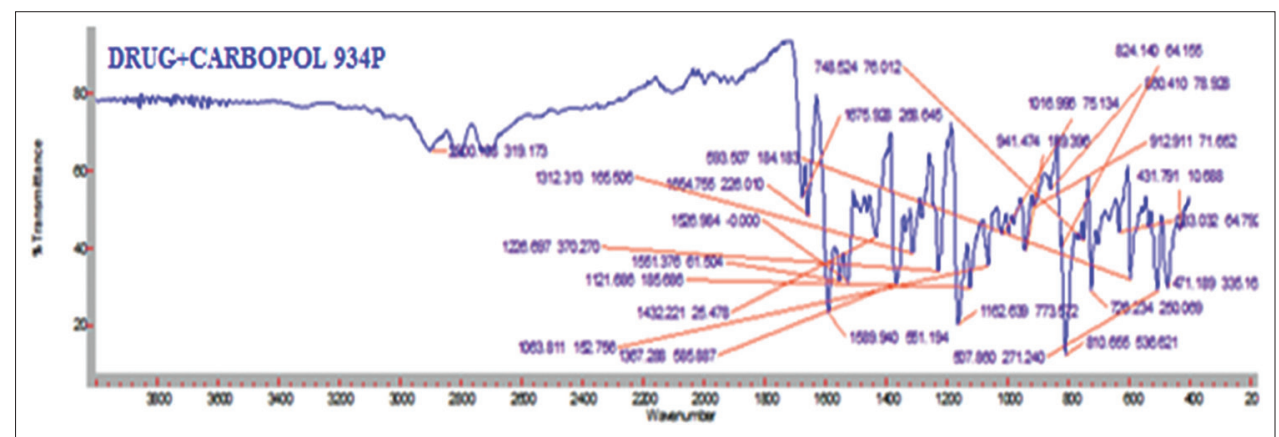

Fig. 8: Fourier transform infrared spectrum of a physical mixture of olmesartan and Carbopol 934P

The cumulative percentage amount of olmesartan permeated through the buccal membrane in first $2 \mathrm{~h}$ was $49.43 \%$, and $84.23 \%$ in $6 \mathrm{~h}$ clearly indicates that the penetration of the drug through the goat buccal epithelium was initially rapid and followed by slow penetration rate. The cumulative percentage amount of olmesartan that had penetrated through the buccal epithelium was shown in Fig. 9. The flux was calculated to be $0.148 \pm 0.168 \mathrm{mg} \mathrm{h}^{-1} \mathrm{~cm}^{-2}$ (Target flux $0.154 \mathrm{mg} \mathrm{h}^{-1} \mathrm{~cm}^{-2}$ ).

Evaluation of physical parameters buccal tablets of olmesartan All the prepared formulations were tested for physical parameters such 
as weight variation, hardness, thickness, and friability and found to be within the pharmacopeia limits. The results of the tests were tabulated in Table 4.

The results of the physical tests of the formulations were within the limits and complied with the standards. The weights of the tablets ranged from $244 \mathrm{mg}$ to $259 \mathrm{mg}$; the thickness was found to be in the range $2.11 \mathrm{~mm}-2.19 \mathrm{~mm}$. The hardness of the tablets was in the range of $4.1-4.7 \mathrm{~kg} / \mathrm{cm}^{2}$ and friability was in the range $0.14-0.24 \%$, indicating that the tablets are hard enough to withstand breakage. The drug content on an average was found to be $98.874 \%$. All these parameters were within acceptable limits. This study indicated that all the prepared formulations were good.

\section{In vitro drug release of buccal tablets}

In vitro, drug release studies were conducted in $\mathrm{pH} 6.8$ phosphate buffer and revealed that the release of olmesartan from different formulations varies with characteristics and composition of the matrix forming polymers as shown in graphs. An increase in the polymer concentration causes an increase in the viscosity of the gel as well as the formation of a gel layer with a longer diffusional path length. This cause a decrease in the effective diffusion coefficient of the drug and that could substantially reduce the penetration of the dissolution medium into the tablet matrix and therefore a reduction in the drug release rate.

The formulations F1-F5 formulated using HPMC K4M, In case of formulation $\mathrm{F} 1$, the rate of drug release was much faster and found to be $99.78 \%$ in $5 \mathrm{~h}$, and formulation $\mathrm{F} 2$ released faster rate than the other formulations in $6 \mathrm{~h}$. Because with an increase in the polymer concentration from $\mathrm{F} 2$ to $\mathrm{F} 5$, the percentage drug release was decreased from $98.72 \%$ to $29.84 \%$ in 6 h. Only the formulation F2 had shown more than $97 \%$ drug release in $6 \mathrm{~h}$. The formulations F6-F10 formulated using SCMC, in case of formulations F6 had shown 99.85\% of drug release in $5 \mathrm{~h}$, respectively. Increasing the concentration of the polymer in the formulation showed the sustained effect on olmesartan release. The percentage of drug release from formulations F7 to F10 was decreased from $99.83 \%$ to $80.38 \%$ in $6 \mathrm{~h}$. For the Carbopol 934P based formulations, the percentage drug release from formulations F11 to $\mathrm{F} 15$ was decreased from $81.63 \%$ to $51.04 \%$ in $6 \mathrm{~h}$ due increase in the polymer concentration. Only F11 formulation showed better release about $81.63 \%$ in a desired period of time and drug release pattern was shown in figures 10-12.

Buccal tablets containing lower concentrations of these polymers tend to release the drug in a shorter period of time. Increasing the concentration of the polymer in the formulation showed the sustained effect on olmesartan release, thus confirming the dominant role of the rapidly hydrating polymer in controlling the release of olmesartan from buccal tablets as seen from dissolution profile. The difference in the drug release profiles of various formulations was due to the release of olmesartan from buccal tablets. The method described by Korsmeyer and peppers was used to describe the mechanism of drug release [33]

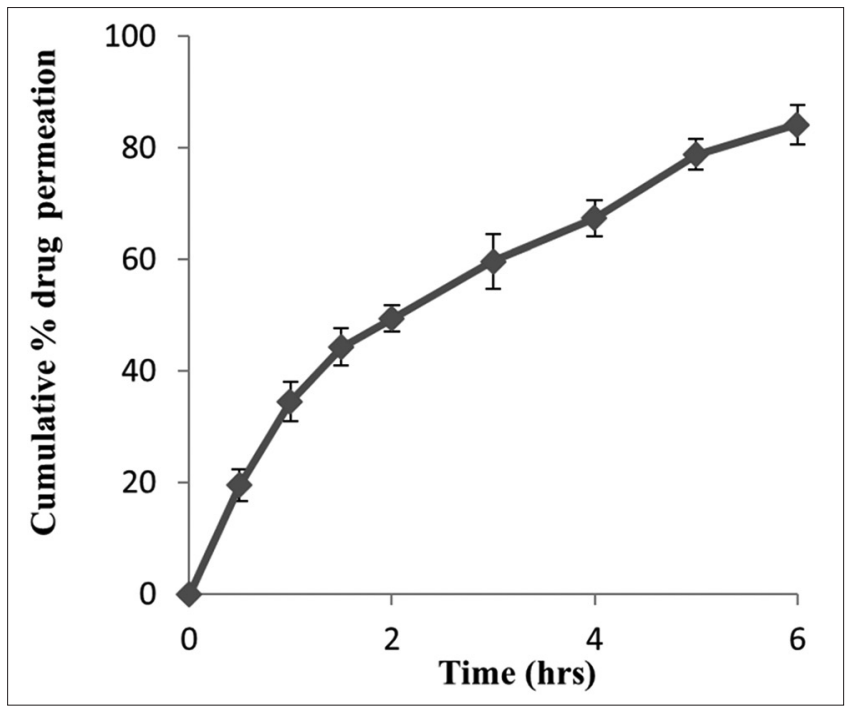

Fig. 9: Ex vivo permeation of olmesartan through goat buccal mucosa

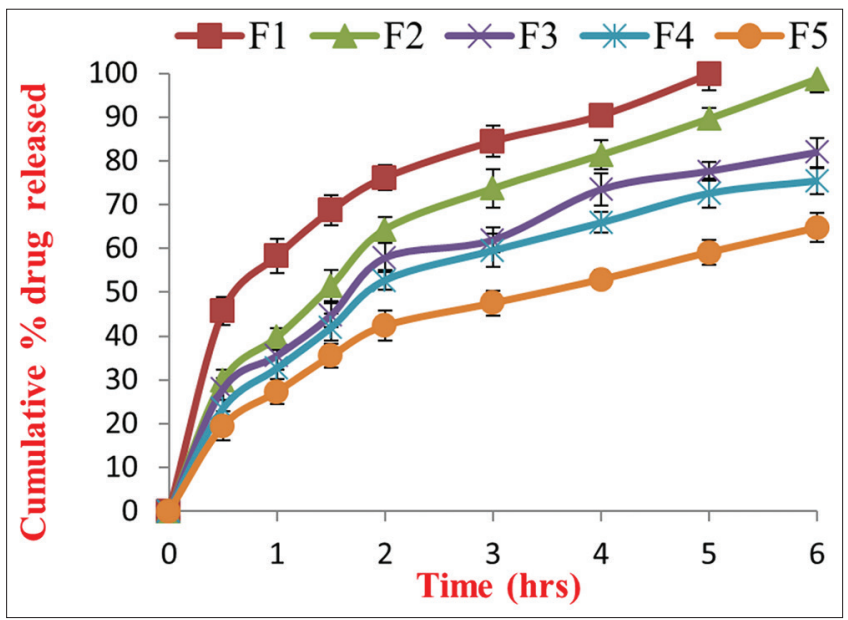

Fig. 10: Cumulative percentage drug release profiles from formulations containing hydroxypropyl methylcellulose. Each value represents the mean \pm Standard deviation $(n=3)$

Table 4: Physicochemical parameters of mucoadhesive buccal tablets of olmesartan

\begin{tabular}{llllll}
\hline Formulation code & Weight variation $\mathbf{( m g )}$ & Thickness $(\mathbf{m m})$ & Hardness $\left.\mathbf{( k g} / \mathbf{c m}^{2}\right)$ & Friability (\%) & Assay (\%) \\
\hline F1 & $254 \pm 1.26$ & $2.14 \pm 0.02$ & $4.1 \pm 0.5$ & 0.14 & 99.57 \\
F2 & $245 \pm 1.43$ & $2.13 \pm 0.03$ & $4.4 \pm 0.3$ & 0.16 & 98.77 \\
F3 & $254 \pm 3.78$ & $2.14 \pm 0.02$ & $4.3 \pm 0.4$ & 0.14 & 98.69 \\
F4 & $253 \pm 2.1$ & $2.15 \pm 0.04$ & $4.5 \pm 0.2$ & 0.23 & 99.32 \\
F5 & $252 \pm 2.25$ & $2.13 \pm 0.03$ & $4.7 \pm 0.3$ & 0.18 & 9.53 \\
F6 & $2.13 \pm 0.03$ & $4.2 \pm 0.2$ & 0.16 & 99.71 \\
F7 & $247 \pm 1.75$ & $2.11 \pm 0.03$ & $4.3 \pm 0.5$ & 0.20 & 98.47 \\
F8 & $250 \pm 1.83$ & $2.2 \pm 0.02$ & $4.5 \pm 0.3$ & 0.13 & 98.81 \\
F9 & $253 \pm 2.24$ & $2.19 \pm 0.04$ & $4.2 \pm 0.4$ & 0.24 & 99.58 \\
F10 & $252 \pm 3.56$ & $4.1 \pm 0.5$ & 0.15 & 97.44 \\
F11 & $259 \pm 2.28$ & $4.5 \pm 0.3$ & 0.14 & 98.96 \\
F12 & $253 \pm 1.91$ & $4.7 \pm 0.5$ & 0.21 & 98.39 \\
F13 & $254 \pm 3.64$ & $4.3 \pm 0.6$ & 0.17 & 97.88 \\
F14 & $258 \pm 2.12$ & $4.16 \pm 0.03$ & 0.15 & 9.19 \\
F15 & $244 \pm 3.32$ & & & 0.19 & 99.33
\end{tabular}

Each value represents the mean $\pm S D(n=3)$. SD: Standard deviation 


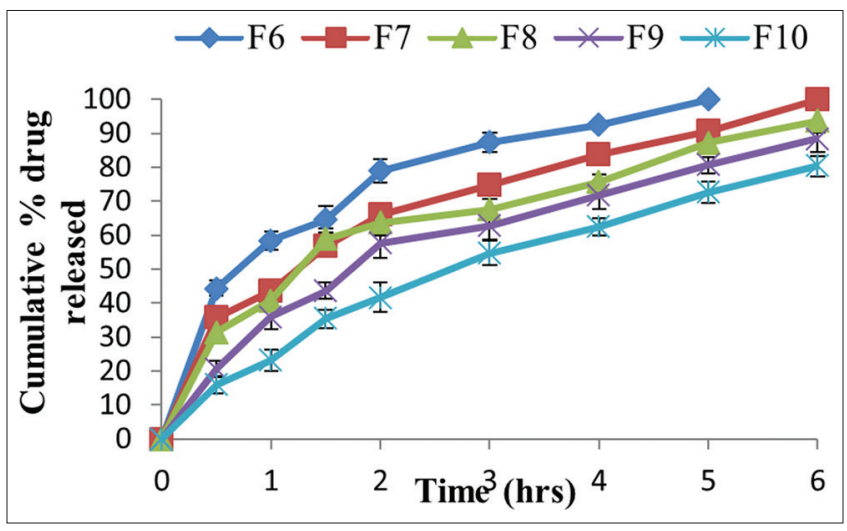

Fig. 11: Cumulative percentage drug release profiles from formulations containing Sodium carboxymethyl cellulose. Each value represents the mean \pm Standard deviation $(n=3)$

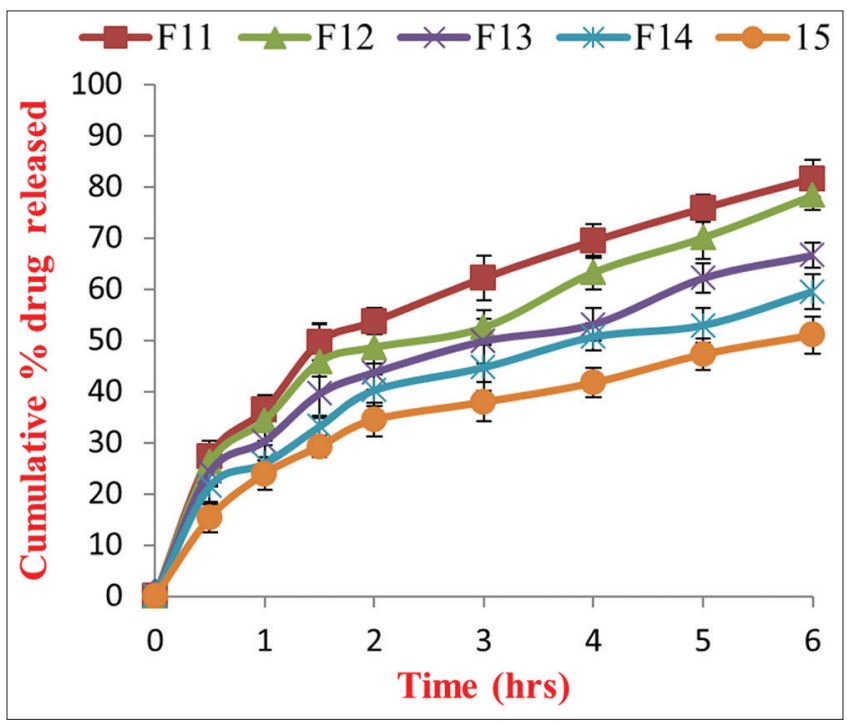

Fig. 12: Cumulative percentage drug release profiles from formulations containing Carbopol 934P

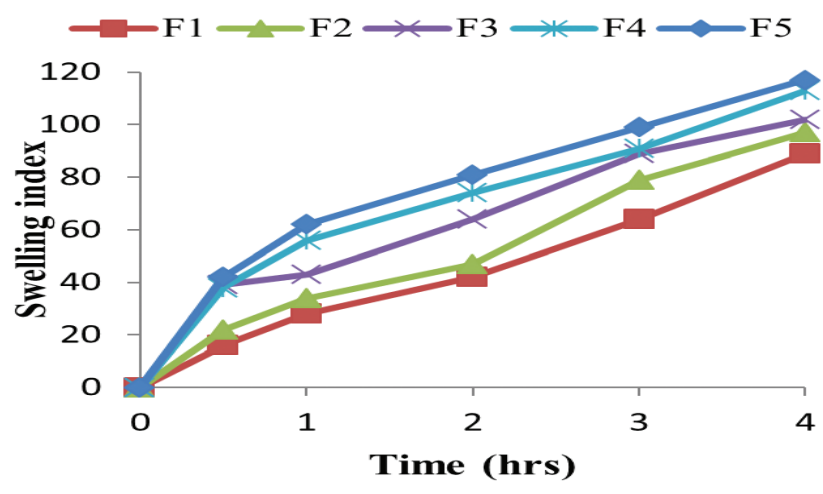

Fig. 13:Swelling index values of hydroxypropyl methylcellulose

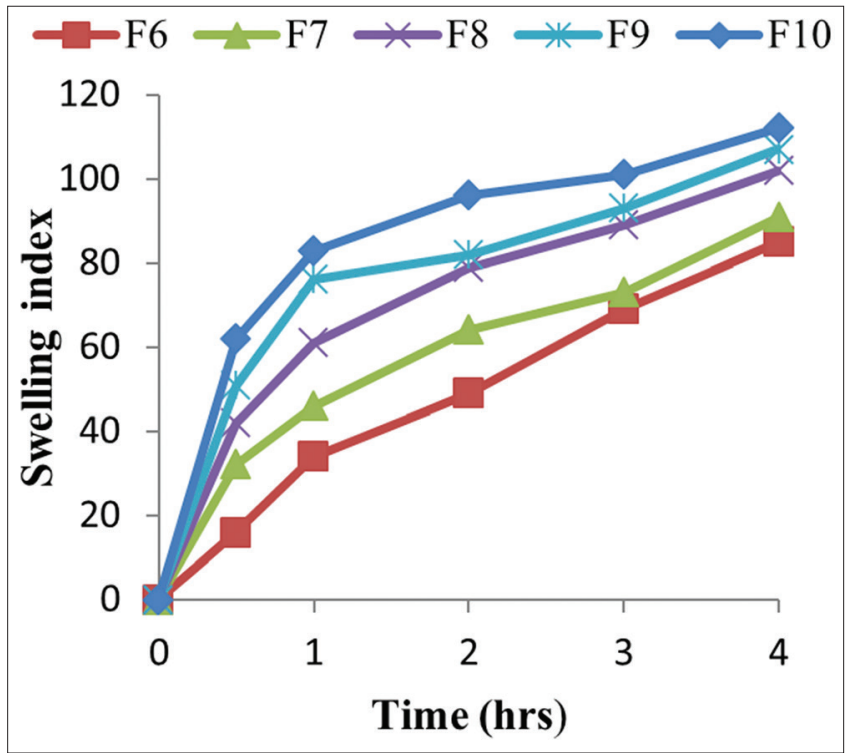

Fig. 14: Sodium carboxymethyl cellulose containing buccal tablets

Table 5: Kinetic parameters for the in vitro release of olmesartan from different formulations

\begin{tabular}{|c|c|c|c|c|c|}
\hline \multirow[t]{2}{*}{ Formulation } & \multirow{2}{*}{$\begin{array}{l}\text { Zero-order } \\
\mathbf{R}^{2} \\
\end{array}$} & \multirow[t]{2}{*}{ First-order } & \multirow[t]{2}{*}{ Higuchi } & \multicolumn{2}{|c|}{ Korsmeyer-Peppas } \\
\hline & & & & & $\mathbf{n}$ \\
\hline F1 & 0.923 & 0.918 & 0.982 & 0.912 & 0.309 \\
\hline F3 & 0.914 & 0.913 & 0.973 & 0.924 & 0.746 \\
\hline $\mathrm{F} 4$ & 0.956 & 0.921 & 0.971 & 0.943 & 0.569 \\
\hline F5 & 0.959 & 0.893 & 0.943 & 0.935 & 0.537 \\
\hline F6 & 0.949 & 0.842 & 0.981 & 0.915 & 0.731 \\
\hline F7 & 0.957 & 0.789 & 0.955 & 0.898 & 0.443 \\
\hline F8 & 0.943 & 0.898 & 0.982 & 0.952 & 0.652 \\
\hline F9 & 0.962 & 0.913 & 0.974 & 0.943 & 0.532 \\
\hline F10 & 0.964 & 0.923 & 0.988 & 0.928 & 0.327 \\
\hline F11 & 0.931 & 0984 & 0.967 & 0.982 & 0.655 \\
\hline F12 & 0.940 & 0.972 & 0.972 & 0.942 & 0.556 \\
\hline F13 & 0.971 & 0.926 & 0.964 & 0.938 & 0.574 \\
\hline F14 & 0.956 & 0.959 & 0.994 & 0.962 & 0.712 \\
\hline F15 & 0.986 & 0.974 & 0.971 & 0.968 & 0.694 \\
\hline
\end{tabular}

presence of different concentrations of polymer. Formulation F2, F7, and F11 was considered as optimized formulations among all these formulations because they released the drug within the desired period of time $6 \mathrm{~h}$.
In vitro release kinetic parameters of olmesartan from mucoadhesive buccal tablets

In vitro drug release data were fitted to zero-order, first-order, Higuchi, and Korsmeyer-Peppas equations to ascertain the pattern of drug 


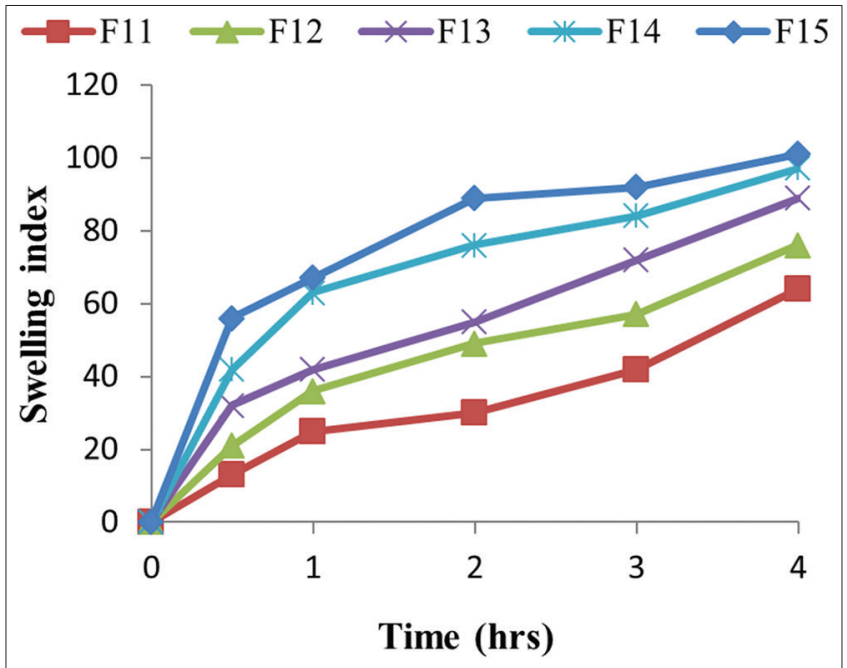

Fig. 15: Swelling index values of Carbopol 934P containing buccal tablets

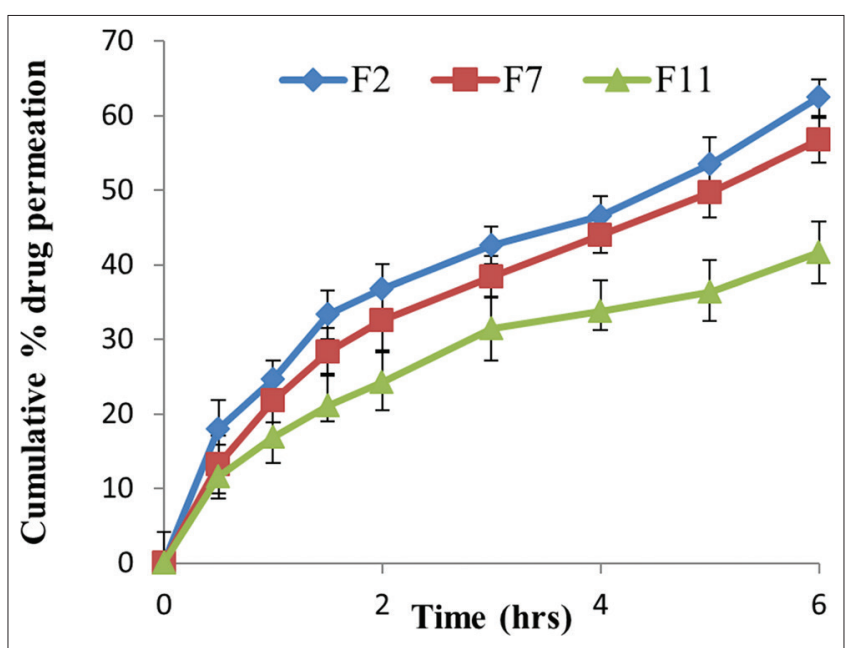

Fig. 16: Ex vivo permeation of olmesartan from optimized formulations through goat buccal mucosa

From Table 5, it could be inferred that the order of release for F2 and F7 was zero-order and F11 was first-order. The mechanism was further confirmed by Korsmeyer-Peppas equation. For formulations F2 and F7, the $\mathrm{n}$ values were 0.421 and 0.441 , indicating Fickian diffusion; whereas, for formulation $\mathrm{F} 11$, the $\mathrm{n}$ value was 0.655 , indicating non Fickian diffusion. It was concluded that the drug release from the tablet matrix followed the diffusion controlled mechanism in all the formulations.

\section{Swelling studies of buccal tablets}

The swelling index values of all the tablets increased with increasing amounts of polymer concentration. Swelling index was calculated with respect to time. The swelling indices of the tablets increased with increasing amounts of HPMC K4M, SCMC, and Carbopol 934P. Appropriate swelling property of a buccal device is essential for uniform and prolonged release of drug and proper mucoadhesion. An increase in the polymer concentration causes an increase in the viscosity of the gel as well as the formation of a gel layer with a longer diffusional path length. This cause a decrease in the effective diffusion coefficient of the drug and that could substantially reduce the penetration of the dissolution medium into the tablet matrix and therefore a reduction in the drug release rate. The maximum swelling index was observed with the formulations F5, F10, and F15. Swelling index profiles of all the formulations at different time points up to $4 \mathrm{~h}$ were represented in Figs. 13-15

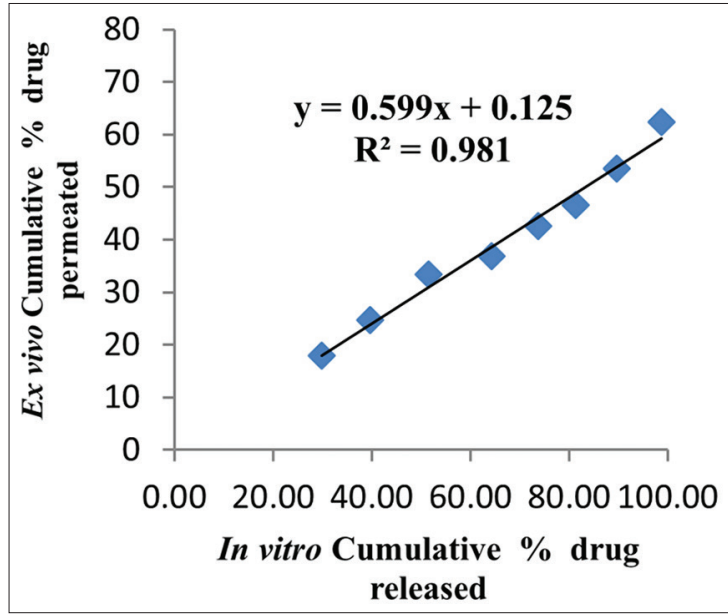

Fig. 17: In vitro ex vivo correlation between cumulative percentage drug released in vitro and percentage drug permeated ex vivo of optimized olmesartan buccal tablets containing hydroxypropyl methylcellulose

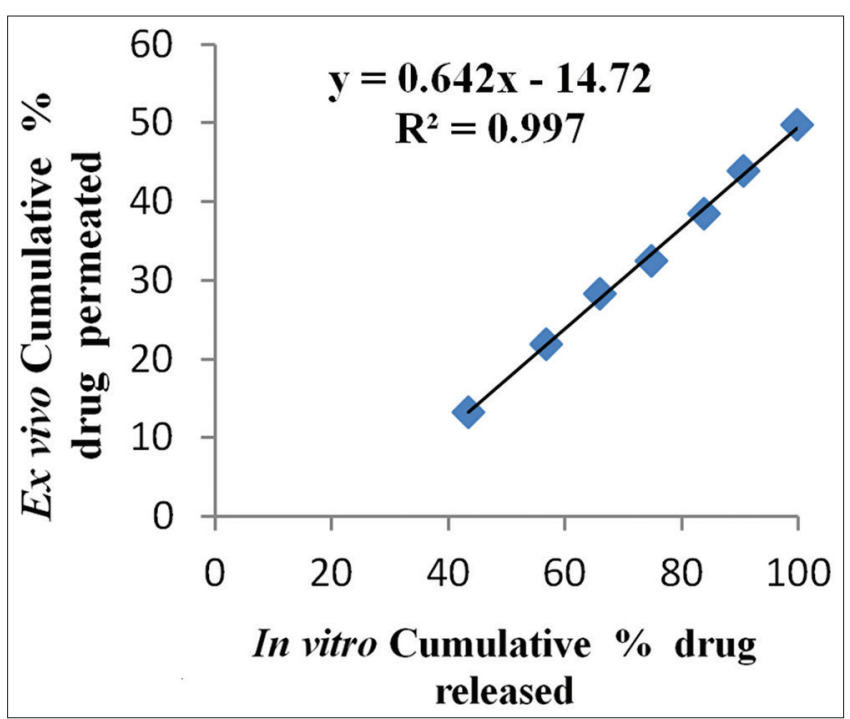

Fig. 18: In vitro ex vivo correlation between cumulative percentage drug released in vitro and percentage drug permeated ex vivo of optimized olmesartan buccal tablets containing b)

Ex vivo mucoadhesion strength, ex vivo mucoadhesive time and surface $\mathbf{p H}$ values of optimized formulations

The surface $\mathrm{pH}$ of the buccal tablets was determined to investigate the possibility of any side effects in vivo. As an acidic or alkaline $\mathrm{pH}$ may cause irritation to the buccal mucosa, it was determined to keep the surface $\mathrm{pH}$ as close to neutral as possible. Surface $\mathrm{pH}$ of the optimized formulations was found to be $6.76 \pm 0.28-6.89 \pm 0.34$. The $\mathrm{pH}$ was found to be near to the neutral, from the results it was found that, the formulations do not cause any irritation to the buccal mucosa. The ex vivo mucoadhesion strength and time of the tablets was determined for optimized formulations using goat buccal mucosa. Surface $\mathrm{pH}$ values, mucoadhesive strength and mucoadhesive time values for the optimized formulations were shown in Table 6.

Ex vivo permeation of olmesartan through goat buccal membrane from optimized buccal tablets

Based on the in vitro drug release of all formulations, the F2, F7, and F11 formulations were selected for ex vivo drug permeation studies. The 
Table 6: Ex vivo mucoadhesive strength, ex vivo mucoadhesive time, and surface $\mathrm{pH}$ values of optimized formulations

\begin{tabular}{llll}
\hline Formulation Code & Mucoadhesive strength (gram force) & Mucoadhesive time (h) & Surface $\mathbf{p H}$ \\
\hline F2 & $13.28 \pm 0.12$ & $6.73 \pm 0.13$ & $6.763 \pm 0.37$ \\
F7 & $26.45 \pm 0.08$ & $6.32 \pm 0.21$ & $6.82 \pm 0.28$ \\
F11 & $32.19 \pm 0.05$ & $6.43 \pm 0.3$ & $6.89 \pm 0.34$ \\
\hline
\end{tabular}

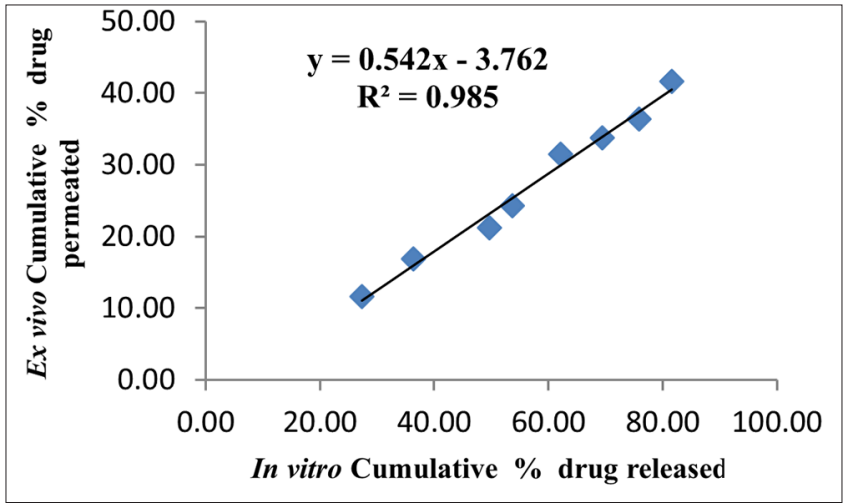

Fig. 19: In vitro ex vivo correlation between cumulative percentage drug released in vitro and percentage drug permeated ex vivo of optimized olmesartan buccal tablets containing Carbopol 934P

results of drug permeation from buccal tablets of olmesartan through the goat buccal mucosa revealed that the drug was released from the formulation and permeated through the buccal membrane and hence could possibly permeate through the human buccal membrane. The results were shown in figure 16, indicated that the drug permeation was slow and steady and $62.45 \pm 2.45 \%, 56.76 \pm 2.98 \%$, and $41.67 \pm 4.21$ of olmesartan could permeate through the buccal membrane from optimized formulations F2, F7, and F11 in $6 \mathrm{~h}$ and the flux was calculated to be $0.975 \pm 1.15 \mathrm{mg} \mathrm{h}^{-1} \mathrm{~cm}^{-2}, 0.954 \pm 0.92 \mathrm{mg} \mathrm{h}^{-1} \mathrm{~cm}^{-2}$, and $0.901 \pm 1.23 \mathrm{mg} \mathrm{h}^{-1} \mathrm{~cm}^{-2}$ (Target flux $0.991 \mathrm{mg} \mathrm{h}^{-1} \mathrm{~cm}^{-2}$ ).

\section{Stability of buccal tablets}

The optimized formulations F2, F7, and F11 showed satisfactory stability in human saliva. There was no change in the color and integrity of the tablets. Physical properties of the buccal tablets such as thickness and diameter are slightly changed due to swelling of the system in human saliva.

In vitro ex vivo correlation between cumulative percentage drug released in vitro and cumulative percentage drug permeated ex vivo of optimized olmesartan buccal tablets

Cumulative percentage of olmesartan permeated through the goat buccal membrane was correlated against cumulative percentage of drug released using in vitro release tests for optimized formulations. The relationship between the percentage of olmesartan released in vitro and percentage of drug permeated ex vivo is shown in Figs 17-19. The straight line and the high correlation coefficient $\mathrm{R}^{2}$ of $0.987,0.997$, and 0.985 for optimized formulations (F2, F7, and F11) proved the good correlation between in vitro drug release and ex vivo drug permeation studies across goat buccal mucosa. Hence, by considering the complete difference in the test conditions of in vitro and ex vivo release studies, the high correlation and coincidence of in vitro and ex vivo release profiles, it can be concluded that such mucoadhesive tablets could be a useful carrier in buccal drug delivery systems.

\section{CONCLUSION}

The mucoadhesive buccal tablets of olmesartan were prepared by direct compression method using mucoadhesive polymers HPMC K4M, SCMC, and Carbopol 934P. FTIR studies concluded that there was no interaction between drug and excipients. The physicochemical properties of all the formulations were shown to be within the limits. Among all the formulations, the formulations F2, F7, and F11 were selected as optimized formulations because they showed satisfactory drug release rates with the Higuchi diffusion controlled release pattern. The optimized buccal tablets possess reasonable mucoadhesive strength, mucoadhesive time, and satisfactory surface pH. Ex vivo permeation studies for optimized tablets were conducted and shown satisfactory drug permeation. This could demonstrate that the optimized formulations could meet the target flux and optimized formulations also showed satisfactory stability in natural human saliva. Ex vivo permeation studies for optimized tablets were conducted and shown satisfactory drug permeation. Good in vitro ex vivo correlation for an optimized buccal tablet of olmesartan demonstrates the validity of the release tests conducted. It was concluded that the development of buccal delivery of olmesartan tablets was one of the potential alternative routes of administration to avoid hepatic first-pass effect and to improve the bioavailability of olmesartan through buccal mucosa and enhance the release of drug for extended period of time, by which these formulations reduce the need for frequent administration and enhance the patient compliance. Hence, this study concludes that the olmesartan could be delivered through the buccal route. Further, work is recommended to support its efficacy claims by pharmacokinetic and pharmacodynamic studies in a human being.

\section{ACKNOWLEDGMENT}

The authors are thankful to Cipla Ltd., Mumbai, India, and Horizon Pharma (Gujarat, India) for providing gift samples. Authors are also thankful to management of School of Pharmacy, Anurag Group of Institutions, Venkatapur, Ghatkesar, Telangana, for their support to carry out research work.

\section{CONFLICTS OF INTEREST}

There are no conflicts of interest.

\section{AUTHOR'S CONTRIBUTION}

All authors contributed to the design and implementation of the research, to the analysis of the results and to the writing of the final manuscript. All authors provided critical feedback and helped shape the research, analysis, and manuscript.

\section{REFERENCES}

1. Patel KV, Patel ND, Dodiya HD, Shelat PK. Buccal bioadhesive drug delivery system: An overview. Indian J Pharma Bioarch 2011;2:275-82. 2. Satyabrata B, Ellaiah M, Chandan M, Murthy KV, Bibhutibhusan P, Kumar PS. Design and in vitro evaluation of mucoadhesive buccal tablets of Perindopril prepared by sintering technique. Asian J Pharm Clin Res 2010;3:4-10.

3. Shojaei AH, Zhuo SL, Li X. Transbuccal delivery of acyclovir (II): Feasibility, system design, and in vitro permeation studies. J Pharm Sci 1998; : $: 66-73$

4. Zhang H, Zhang J, Streisand JB. Oral mucosal drug delivery: Clinical pharmacokinetics and therapeutic applications. Clin Pharm 2002:41:661-80.

5. Kadam SS, Yeole DH, Unjavani HK, Ganure AG, Kabra RP. Formulation and evaluation of mucoadhesive buccal tablets containing Carvedilol. Int J Curr Pharm Res 2014;1:67-80.

6. Senel S, Kremer MJ, Ka SH, Wertz PW, Hincal AA, Squier CA. Enhancing effect of Chitosan on peptide drug delivery across Buccal mucosa. Biomaterials 2000;21:2067-71.

7. Peddapalli H, Chinnala KM, Banala N. Design and in vitro characterization of mucoadhesive buccal patches of duloxetine 
hydrochloride. Int J Pharm Pharm Sci 2017;9:52-9.

8. Jaffar IS, Maraie NK. Formulation and in vitro evaluation of buccal mucoadhesive tablets of promethazine HCl. Int J Pharm Sci Rev Res 2014;24:61-9.

9. Patel MC, Patil CC. Formulation and evaluation of mucoadhesive buccal tablets of repaglinide. RGUHS J Pharm Sci 2014;4:34-42.

10. Roy AK, Kumar V, Basha SJ, Haque R, Karki R. Formulation and evaluation of Mucoadhesive buccal tablets of Valsartan. Int J Drug Dev Res 2013;5:145-58.

11. Shayeda, Ramesh G, Reddy PC, Rao YM. Development of novel bioadhesive buccal formulation of diltiazem: In vitro and in vivo characterization. PDA J Pharm Sci Tech 2009;63:1-9.

12. Vishnu YV, Sekhar KC, Rao ME, Rao YM. Development and in vitro evaluation of buccoadhesive Carvedilol tablets. Acta Pharm 2007;57:185-97.

13. Patil P, Kulkarni SV, Rao BS, Ammanage A, Surpur C, Basavaraj. Formulation and in vitro evaluation of mucoadhesive tablets of ofloxacin using natural gums. Int J Curr Pharm Res 2011;3:93-8.

14. Ishida M, Nambu N, Nagai T. Ointment-type oral mucosal dosage form of carbopol containing Prednisolone for treatment of aphtha. Chem Pharm Bull (Tokyo) 1983;31:1010-14.

15. Ahuja A, Khar RK, Ali J. Mucoadhesive drug delivery systems. Drug Dev Ind Pharm 1997;23:489-17.

16. Bromberg LE, Buxton DK, Friden PM. Novel periodontal drug delivery system for treatment of periodontitis. Control Release 2001;71:251-9.

17. Dortunc B, Ozer L, Uyanik N. Development and in vitro evaluation of a Buccoadhesive pindolol tablet formulation. Drug Dev Ind Pharm 1998;24:281-8.

18. Sudhakar Y, Kuotsu K, Bandyopadhya AK. Buccal bioadhesive drug delivery. A promising option for orally less efficient drugs. J Control Rel 2006;114:15-40.

19. Reddy PC, Rao YM. Buccal Drug Delivery Systems. In: Advances in Drug Delivery. Vol. 01. India: Published by Pharma Book Syndicate; 2010. p. 139-210.

20. Kumar V, Zakir F, Agarwal G, Choudhary A. Formulation and evaluation of buccal patches of venlafaxine. Int J Pharm Biosci 2011;1:170-82.

21. Warner GT, Jarvis B. Olmesartan medoxomil. Drugs 2002;62:1345-53.
22. Nakagomi-Hagihara R, Nakai D, Kawai K, Yoshigae Y, Tokui T, Abe T, et al. OATP1B1, OATP1B3, and Mrp2 are involved in hepatobiliary transport of olmesartan, a novel angiotensin II blocker. Drug Metab Disposition 2006;34:862-9.

23. Gupta A, Garg S, Khar RK. Measurements of bioadhesive strength of buccal tablets: Design of an in vitro assembly. Indian Drugs 1993;30:152-55

24. Patel DM, Shah PM, Patel CN. Formulation and evaluation of bioadhesive buccal drug delivery of repaglinide tablets. Asian J Pharm 2012;6:171-9.

25. Channawar MA, Bakde BV, Gawnde SR, Chandewar AV, Kshirsagar MD. Development and in vitro characterization of diltiazem buccal tablets. J Pharm Res 2012;5:908-12.

26. Velmurugan S, Srinivas P. Formulation and in vitro evaluation of losartan potassium mucoadhesive buccal tablets. Asian J Pharm Clin Res 2013;6:125-30.

27. Bottenberg P, Cleymaet R, Muynek CD, Remon JP, Coomans D, Slop D. Development and testing of bioadhesive, fluoridecontaining slow-release tablets for oral use. J Pharm Pharmacol 1991;43:457-64.

28. Shaik K, Shanmugam V, Angilicam A, Rao SS, Shaik K. Formulation and evaluation of famotidine buccal tablets. Int J Curr Pharm Res 2014;5:410-7.

29. Patel VM, Prajapati BG, Patel HV, Patel KM. Mucoadhesive bilayer tablets of propranolol hydrochloride. AAPS Pharm Sci Tech 2007;8:1-6.

30. Kumar BP, Kavitha P, Devi KJ. Formulation design and evaluation of mucoadhesive buccal tablets of nitroglycerin. Int J Pharm Pharm Sci 2014;6:251-9.

31. Nagaraju K, Velmurugan S, Deepika B, Vinushitha S. Formulation and in vitro evaluation of buccal tablets of metoprolol tartrate. Int J Pharm Pharm Sci 2011:3:239-46.

32. Patel VM, Prajapati BG. Design and in vitro characterization of Eudragit containing mucoadhesive buccal patches. Int J Pharma Pharm Sci 2011;3:783-9.

33. Korsmeyer RW, Gurny R, Doelker E, Buri P, Peppas NA. Mechanism of solute release from porous hydro-matrices and other factors may be responsible. Int J Pharm 1983;15:25-35. 